\title{
Educating General Internists for Kansas
}

K. James Kallail, Ph.D.

University of Kansas School of Medicine-Wichita

Department of Internal Medicine

\begin{abstract}
Background. The demand for primary care is increasing, yet fewer medical school graduates are entering primary care residencies and fewer residency graduates are targeting their careers toward primary care. The University of Kansas School of Medicine-Wichita (KUSM-W) was created specifically to enrich primary health care in the state. This project examined the impact of the Department of Internal Medicine's postgraduate education program on the supply of generalist physicians to Kansas.

Methods. Residency match data over 19 years were analyzed to determine the number of KUSM-W medical students who matched in internal medicine. Practice setting data for internal medicine and internal medicine/pediatrics residency graduates over 16 years were analyzed to determine type and location of practice.

Results. Over 19 years, an average of $20 \%$ of KUSM-W medical students matched to an internal medicine residency. A downward trend toward an internal medicine residency was noted over time. Over 16 years, 54\% of residency graduates entered primary care practice with the majority staying in Kansas. Twelve percent entered primary care practice in rural communities under 20,000 population.

Conclusions. KUSM-W provides a valuable service by graduating a respectable proportion of medical students to internal medicine residencies and a large proportion of residents to primary care practice. Many of the issues that attract students and residents to primary care, however, are not under the direct influence of the medical education system. Changes in health policy, particularly reimbursement and health care delivery issues, will have more impact on primary care workforce than changes in medical education. KJM 2007; 1(1):2-6.
\end{abstract}

\section{Introduction}

Primary care in the US is on death row declared a recent editorial. ${ }^{1}$ An American College of Physicians report stated that primary care is at grave risk of collapse. The demand for primary care is increasing, yet fewer medical school graduates are entering primary care residencies and fewer residency graduates are targeting their careers toward primary care. ${ }^{1,2}$ The proportion of physicians seeking subspecialty training has increased. ${ }^{3}$ Further, the attrition rate of primary care physicians due to career options and retirement is expected to increase. Money and lifestyle are the main culprits behind the decline in primary care.
National data on third-year internal medicine residents' career choices showed the trend away from primary care. ${ }^{4}$ Since 2000 , the percentage of graduates entering generalist practices declined by half from over $40 \%$ to about $20 \%$. Over half of the graduates selected sub-specialty careers. The number entering hospital medicine practices has grown to over $10 \%$.

Shortages of primary care physicians in Kansas are long-standing problems. As of the latest state report ${ }^{5}, 82$ of 105 Kansas counties were designated, wholly or partially, as federal Primary Medical Care Health Professional Shortage Areas. In addition, 53 of 105 counties are designated 
by state definitions as medically underserved. Finally, 90 counties are eligible for federally-designated Rural Health Clinics, an effort to increase recruitment of physicians to medically underserved areas. In total, 99 of 105 Kansas counties are designated, wholly or partially, by one of the various definitions as medically underserved for primary care.

The University of Kansas School of Medicine-Wichita (KUSM-W) was created specifically to enrich primary health care in the state. KUSM-W is a community-based medical school whose primary mission is to train physicians for the state of Kansas. The purpose of this project was to examine the impact of the Department of Internal Medicine's postgraduate education program on the supply of generalist physicians to Kansas.

\section{Methods}

Residency match data from the KUSMW Office of Academic and Student Affairs was compiled on graduating medical students for the years 1988 through 2006. In addition, graduate data for the Department of Internal Medicine residency program for the years 1991 through 2006 were obtained from departmental records. Graduates from the Internal Medicine/Pediatrics (Med/Peds) combined program were reviewed beginning in 1998 through 2006. The first Med/Peds graduation occurred in 1998. The initial practice location following residency was reviewed to determine the geographic setting and community size. In addition, the type of initial practice was assessed.

US Census Bureau data were used to determine community population and rural status. ${ }^{6}$ Data from the 1990 and 2000 census were used as appropriate. Rural status was defined as a non-metropolitan statistical area with a population less than 20,000. A primary care practice was defined as a generalist practice with continuity of care. Practices specifically excluded from the primary care category included emergency medicine, occupational medicine, hospital medicine, and fellowship training.

\section{Results}

From 1988-2006, an average of 20\% of KUSM-W medical students matched to an internal medicine residency (regardless of location). The percentages ranged from a high of $30 \%$ in 1992 to a low of $11 \%$ in 1997. Figure 1 reveals a downward trend in the percent of students who matched to an internal medicine residency.

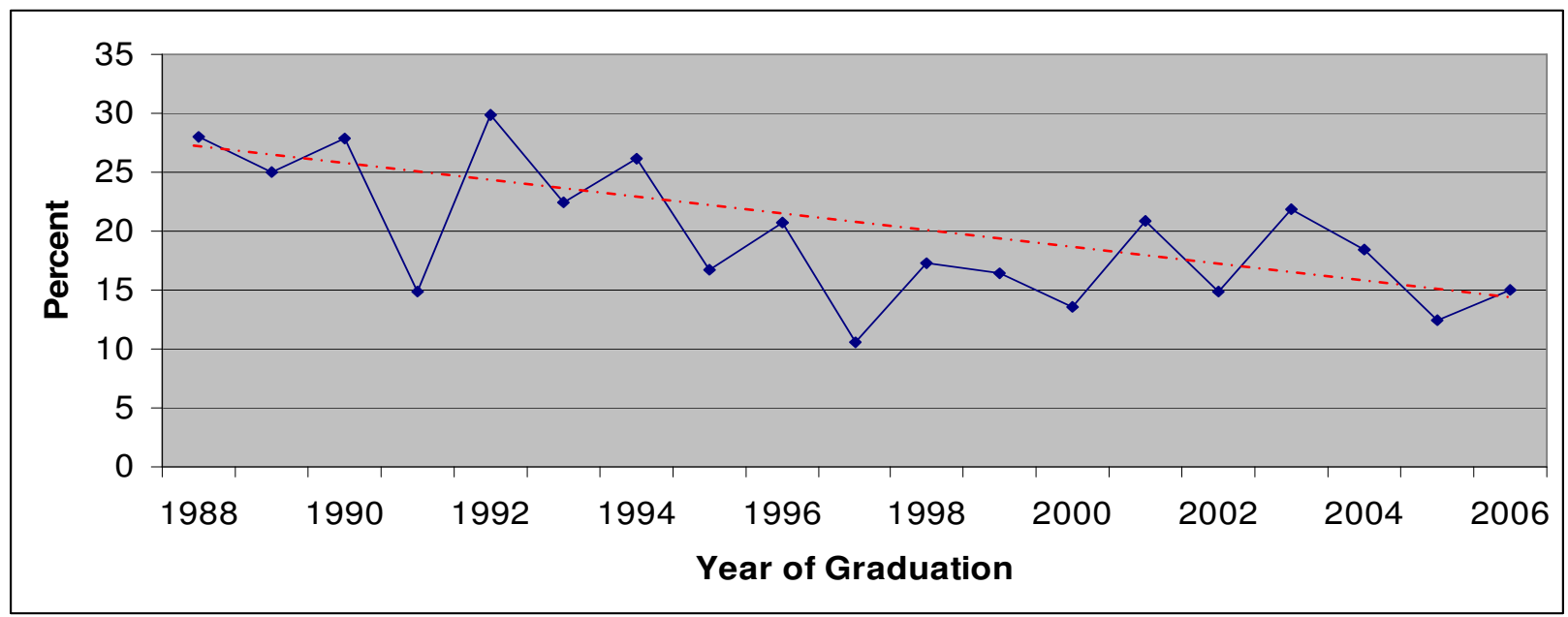

Figure 1. Percent of KUSM-W Medical Students Who Matched to Internal Medicine Programs by Year. (The red line is only an aid to visualize the decline over time.) 
From 1991-2006, 169 individuals graduated from the KUSM-W residency program in either internal medicine $(\mathrm{n}=$ $155)$ or Med/Peds $(n=14)$. Table 1 shows the breakdown of graduates by practice setting. Of the 169 graduates, 92 (54\%) entered primary care practice. Approximately one-third (35\%) entered subspecialty fellowship training. The remainder (11\%) practiced emergency medicine, occupational medicine, or hospital medicine.

Figure 2 shows the practice setting of the internal medicine residency graduates by year. Generally, the number of graduates entering primary care practice shadowed the total number until 2005. The number of graduates entering fellowship showed an upward trend since 2005 when more graduates entered a fellowship than primary care practice.

Internal medicine graduates who practiced primary care tended to stay in Kansas. About three-quarters of the graduates $(78 \%)$ who practiced primary care stayed in Kansas. Of those who practiced in rural communities, $73 \%$ stayed in Kansas. A smaller percentage of Med/Peds graduates entered primary care practices than internal medicine graduates. More entered other practice settings, particularly in hospital medicine. Although the total number of Med/Peds graduates is small, all who entered primary care practice stayed in Kansas.

Table 1. Breakdown of KUSM-W Internal Medicine and Internal Medicine/Pediatrics Graduates by practice setting.

\begin{tabular}{|c|c|c|c|}
\hline Practice Setting & $\begin{array}{c}\text { Internal Medicine } \\
\text { Residency } \\
\mathrm{n}=155 \\
(\%)\end{array}$ & $\begin{array}{c}\text { Internal Medicine/ } \\
\text { Pediatrics Residency } \\
\mathrm{n}=14 \\
(\%)\end{array}$ & $\begin{array}{c}\text { Total } \\
\mathrm{n}=169 \\
(\%)\end{array}$ \\
\hline Primary Care Practice & $\begin{array}{c}88 \\
(57) \\
\end{array}$ & $\begin{array}{c}4 \\
(29) \\
\end{array}$ & $\begin{array}{c}92 \\
(54) \\
\end{array}$ \\
\hline Primary Care Practice in Kansas & $\begin{array}{c}69 \\
(45)\end{array}$ & $\begin{array}{c}4 \\
(29)\end{array}$ & $\begin{array}{c}73 \\
(43)\end{array}$ \\
\hline Rural Primary Care & $\begin{array}{c}26 \\
(17)\end{array}$ & $\begin{array}{c}1 \\
(7)\end{array}$ & $\begin{array}{c}27 \\
(16)\end{array}$ \\
\hline Rural Primary Care in Kansas & $\begin{array}{c}19 \\
(12)\end{array}$ & $\begin{array}{c}1 \\
(7)\end{array}$ & $\begin{array}{c}20 \\
(12)\end{array}$ \\
\hline Fellowship program & $\begin{array}{c}57 \\
(37)\end{array}$ & $\begin{array}{c}2 \\
(14)\end{array}$ & $\begin{array}{c}59 \\
(35)\end{array}$ \\
\hline Other Practice Settings & $\begin{array}{l}11 \\
(7)\end{array}$ & $\begin{array}{c}8 \\
(57)\end{array}$ & $\begin{array}{c}19 \\
(11)\end{array}$ \\
\hline
\end{tabular}

\section{Discussion}

The demand for general internists will increase by $38 \%$ by $2020 .^{2}$ Thirty-five percent of physicians nationwide likely will retire in the next ten years. Yet, changes in the health care system have made primary care less satisfying for physicians and less attractive for students and residents. ${ }^{2,4,7}$ The
KUSM-W Internal Medicine program is experiencing declining interest in primary care as are programs nationwide. However, the long-term view of the KUSM-W Internal Medicine program reveals that the decline is more recent and less severe than the national data suggest. The 16-year average for 
residency graduates to enter a primary care practice is $57 \%$ with the majority staying in Kansas. The 2005 national data revealed that $20 \%$ of internal medicine residency graduates entered primary care. The comparable KUSM-W value was $40 \%$. During the same year, $58 \%$ of graduates entered fellowship nationally. Only $50 \%$ of KUSM-W graduates entered fellowship that year. Certainly, these data revealed some success in preparing general internists for practice in Kansas.

Although the downward trend for KUSM-W medical students to enter an internal medicine residency is concerning, the 19-year average of $20 \%$ was near the national percentage of available positions. In 2006, 22\% of all available residency positions were designated for internal medicine. ${ }^{8} \quad$ KUSM-W medical students, therefore, matched in internal medicine, on average, at about the same proportion of total residency positions available for internal medicine.

The decline in interest for primary care is multifactorial. The system for financing health care and the health care delivery system are problematic. Specialist income in 2004 was approximately double that of primary care physicians. ${ }^{4}$ This gap is unlikely to narrow anytime soon. The reimbursement system favors procedural skills and quantity, rather than quality, of care. ${ }^{4}$ Medicare, the largest purchaser of health care in the US, undervalues evaluation and management services. $^{2}$ Generalist physicians are frustrated by the growing demand for services without inadequate reimbursement.

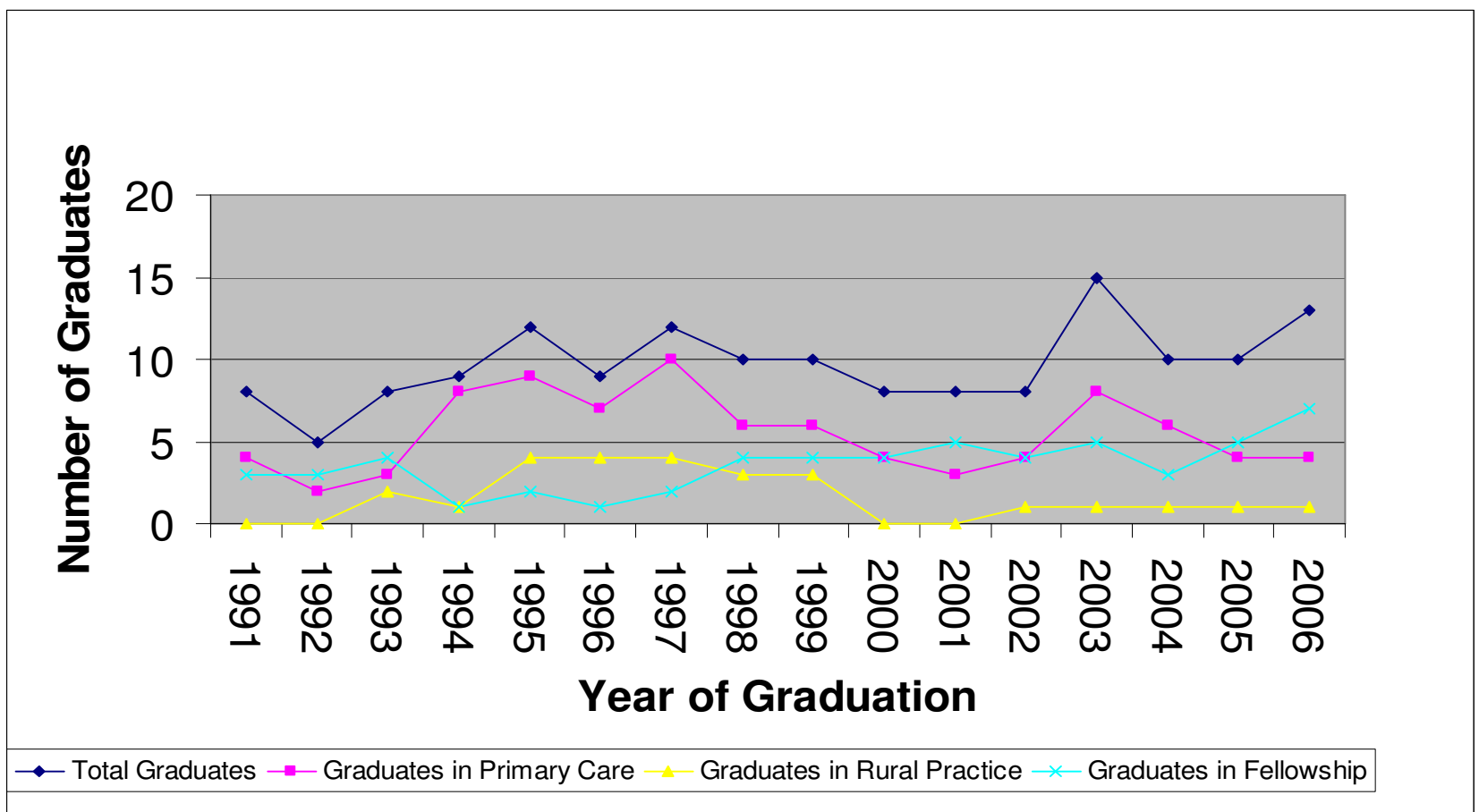

Figure 2. Number of KUSM-W Internal Medicine residency graduates over 16 years by practice setting.

Yet, the demand for primary care services is increasing. The increased prevalence of chronic disease and the aging of the population are factors driving the need for primary care. ${ }^{4}$ Patients want a personal, comprehensive, and longitudinal 
relationship with their doctors, especially within a fragmented health care system. ${ }^{7}$ Primary care services reduce health care costs and improve quality of care. ${ }^{2,7}$ Further, primary care services may result in more appropriate use of specialists who focus on their specific area of expertise. ${ }^{2}$

Educating general internists for Kansas is one responsibility of KUSM-W. Many of the issues that attract students and residents to primary care, however, are not under the direct influence of the medical education system. Changes in health policy,

\section{References}

${ }^{1}$ Reuben DB. Saving primary care. Am J Med 2007; 120:99-102.

2 American College of Physicians. The impending collapse of primary care medicine and its implications for the state of the nation's health care. Washington, DC: American College of Physicians, 2006. Accessed at: www.acponline.org/ hpp/statehc06_1.pdf.

3 Brotherton SE, Rockey PH, Etzel SI. US graduate medical education, 2004-2005. Trends in primary care specialties. JAMA 2005; 294:1075-1082.

4 Bodenheimer T. Primary care - Will it survive? N Engl J Med 2006; 355:862864.

${ }^{5}$ Kansas Department of Health and Environment. Primary Care Health Professional Underserved Areas Report. Kansas 2005. Topeka, KS: Kansas Department of Health and Environment, 2005. Accessed at:

http://www.kdheks.gov/olrh/download/PC UARpt.pdf. particularly reimbursement and health care delivery issues, will have more impact on primary care workforce than changes in medical education. Given the current health care environment, KUSM-W provides a valuable service by graduating a respectable proportion of medical students to internal medicine residencies and a large proportion of residents to primary care practice. Although the trends are concerning and must be addressed, the long-term outcomes have been positive.

${ }^{6}$ US Census Bureau. Decennial Census. Washington, DC: US Census Bureau, 2007. Accessed at:

http:// factfinder.census.gov/home/saff/ main.html?_lang=en.

${ }^{7}$ Woo B. Primary care - The best job in medicine? N Engl J Med 2006; 355:864866.

${ }^{8}$ Alliance for Academic Internal Medicine. 2006 match results. Washington, DC: Alliance for Academic Internal Medicine, 2006. Accessed at: www.im.org/AAIM/ PublicPolicy/Docs/2006MatchData.htm.

Keywords: medical education, graduate medical education, internal medicine, primary care, Kansas 